\title{
Barreiras para implementação da gestão verde da cadeia de suprimento em uma distribuidora de óleo lubrificante
}

\author{
Barriers to the implementation of green supply chain management in a distributor of lubricating oil
}

\author{
Anete Petrusch do Nascimento', Fabiane Padilha da Silva², Adão Alberto Blanco Nunes ${ }^{3}$, Miguel Afonso \\ Sellitto ${ }^{4}$
}

\author{
'Mestranda em Engenharia de Produção e Sistemas pelo PPGEPS,UNISINOS, Brasil \\ ${ }^{2}$ Mestranda em Economia pelo PPGE,UNISINOS, Brasil \\ ${ }_{3}^{3}$ Mestrando em Ciências Contábeis pelo PPGCC,UNISINOS, Brasil \\ ${ }^{4}$ Professor e pesquisador do PPGEPS,UNISINOS, Brasil
}

\begin{abstract}
Resumo
O objetivo deste artigo é apontar quais são as barreiras que impedem que uma empresa da cadeia de suprimentos de óleos lubrificantes implemente práticas ambientalmente amigáveis de gestão, dentro do contexto da Gestão Verde da Cadeia de Suprimentos. O método de pesquisa foi o estudo de caso exploratório em uma distribuidora de óleos lubrificantes. Por revisão bibliográfica, um modelo com cinco categorias e quarenta e sete variáveis foi construído. O modelo foi investigado em uma empresa de distribuição da cadeia de óleos lubrificantes, no qual quatro barreiras foram consideradas importantes: dificuldades nas parcerias ambientais com os fornecedores; o alto custo de embalagens ambientalmente amigáveis; o alto custo de eliminação de resíduos perigosos, e despesa na coleta de produtos usados. A primeira barreira está relacionada a dificuldades na terceirização de serviços. As demais tratam-se de barreiras que impactam no desempenho financeiro da operação.
\end{abstract}

Palavras-chave: Gestão da Cadeia Verde de Suprimentos, GSCM, Barreiras, Óleo lubrificantes, Logística reversa.

\begin{abstract}
The purpose of this article is to point out what are the barriers that prevent a company belonging to the supply chain of lubricating oils to implement environmentally friendly management practices within the context of Green supply chain Management. The research method was the exploratory case study in a distributor of lubricating oils. Based on a bibliographical review, a model with five categories and forty-seven variables was built. The model was investigated in a distribution company of lubricating oils, in which four barriers were considered important: difficulties in environmental partnerships with suppliers; the high cost of environmentally friendly packaging; the high cost of disposal of hazardous wastes, and expenditure on collecting used products. The first barrier is related to difficulties in outsourcing services. The others are barriers that impact the financial performance of the operation.
\end{abstract}

Keywords: Green Supply Chain Management, GSCM, Barriers, Lubricating oil, Reverse logistics 


\section{INTRODUÇÃO}

Empresas têm buscado melhorar seu desempenho ambiental por meio de um conjunto de práticas conhecido como Gestão Verde da Cadeia de Suprimento (GSCM - Green Supply Chain Management) (TESTA e IRALDO, 2010). A GSCM possibilita às empresas reduzir o impacto ambiental que suas atividades causam sem abrir mão de outros atributos de desempenho estratégico, tais como qualidade, custo, confiabilidade, flexibilidade ou serviços associados ao produto (ZHU et al., 2012). Para tanto, é necessário atender não somente às exigências regulatórias ambientais, mas também buscar lucros e compensações econômicas com os esforços de redução de danos ambientais (SRIVASTAVA, 2007). A premissa da sustentabilidade ambiental pode e deve ser assumida pela estratégia da empresa, o que implica desenvolver processos, produtos e serviços ambientalmente adequados (GREEN JR et al., 2012). Abordagens apresentadas na literatura têm incluído aspectos normativos que podem auxiliar na busca de desempenhos ambientais superiores (BRITO e BERARDI, 2010).

Segundo Srivastava (2007), uma definição para GSCM é a integração do pensamento ambiental na gestão da cadeia de suprimentos, o que inclui desde o desenvolvimento do produto, passando pelo fornecimento das matérias primas, fabricação, entrega do produto para os consumidores e da gestão do produto após término da sua vida útil. Sarkis et al. (2011) definem GSCM como a integração das preocupações ambientais nas práticas interorganizacionais na gestão da cadeia de suprimentos.

O interesse pela complexidade envolvida no tema também vem aumentando entre pesquisadores (SRIVASTAVA, 2007; ZHU et al., 2013). À medida que crescem as preocupações com as questões ambientais, mais relevante o tema se torna (SRIVASTAVA, 2008). Como uma forma de organizá-lo e propor um quadro de trabalho que apoie e organize esforços de pesquisa, Sellitto et al. (2013) identificaram três grandes campos de estudo para a GSCM: Estratégia, Inovação e Operações. Uma das áreas estudadas em estratégia de gestão verde refere-se a barreiras e estímulos à implantação de iniciativas ambientalmente amigáveis nas empresas e nas respectivas cadeias de suprimento a que pertencem. Usando o quadro de trabalho e a nomenclatura dos autores, esta pesquisa enquadra-se no campo de estudo Estratégia em GSCM, na área A4, barreiras e estímulos.

Pesquisas sobre estímulos e barreiras para a implantação de GSCM foram realizadas junto a empresas no Reino Unido (HOLT e GHOBADIAN, 2009), em países da Comunidade Europeia (TESTA e IRALDO, 2010), na China (ZHU et al., 2013), (HUANG et al., 2012), na India (BARVE e MUDULI, 2013; GOVINDAN et al., 2014) e no Brasil (ALVES e NASCIMENTO, 2013; JABBOUR et al., 2013). Esses autores mencionam que há poucos estudos a respeito do tema, apesar do interesse crescente, tanto de pesquisadores quanto de profissionais interessados na sua implantação nas empresas.

Srivastava (2007) afirma que muito ainda há para ser pesquisado em GMSC. Apesar de muitos estudos empíricos, mais estudos de caso em profundidade deveriam ser realizados a fim de verificar, por exemplo, o comprometimento organizacional de empresas dentro da GMSC. Estudos empíricos comparando realidades de outros países a exemplo de Brasil, China, México e Rússia em relação a países desenvolvidos também são oportunidades de pesquisa que podem e devem ser exploradas (SRIVASTAVA, 2008). A troca de experiências entre empresas de países desenvolvidos e em desenvolvimento deveria ser mais bem investigada quanto a questões ambientais (ZHU et al., 2013).

Ao fazer uma análise sobre mais de 500 artigos referentes à GSCM publicados no período de 1995 a 2010, Govindan et al. (2014) concluíram que poucos artigos tratavam de países em desenvolvimento. Considerando que uma indústria não necessariamente compartilha a mesma opinião globalmente, estudos sobre a realidade desses países são essenciais. Ademais, esses autores apontam para lacunas de pesquisa na identificação das barreiras que dificultam a implementação da GSCM (GOVINDAN et al., 2014). Barve e Muduli (2011) afirmam que ainda há um considerável número de indústrias que relutam em adotar a GSCM. Também afirmam que poucos estudos têm enfocado as barreiras para a sua implementação. Jabbour et al. (2013) sugerem que se estudem barreiras à GSCM em empresas e cadeias do Brasil, dado que este país faz parte das mais importantes economias emergentes - o BRIC (Brasil, Rússia, Índia e China) e que faltam pesquisas qualitativas baseadas em estudos de casos brasileiros.

Considerando o que foi exposto, a questão de pesquisa para este artigo é: dado o pressuposto de que há barreiras para a plena implementação da GSCM em empresas brasileiras, quais são os fatores predominantes e relevantes para o contexto brasileiro, que bloqueiam iniciativas ambientais em uma empresa integrante da cadeia de suprimentos de óleos lubrificantes e por quê? O método de pesquisa foi o estudo de um caso. O objetivo geral do artigo foi: apontar quais são as barreiras que impedem 
que uma empresa da cadeia de suprimentos de óleos lubrificantes implemente práticas ambientalmente amigáveis de gestão, a GSCM. Os objetivos específicos foram: formar um referencial teórico com barreiras já relatadas na literatura; e estudar uma empresa para verificar quais destas barreiras atuam na empresa e dificultam ou impedem a implementação de práticas ambientalmente amigáveis.

Para isso foi realizado um estudo de caso em uma empresa distribuidora de óleos lubrificantes fabricados por uma grande produtora de combustíveis, que opera no Rio Grande do Sul. Dada a pesquisa prévia de Govindan et al. (2014) que identificou 47 barreiras para a implantação da GSCM, este estudo procurou verificar quais destas são barreiras no contexto da cadeia de óleos lubrificantes e quais impactam diretamente na empresa estudada.

Este artigo está estruturado em quatro capítulos. O primeiro introduz o tema de interesse e apresenta alguns achados e lacunas de pesquisa. Seguem a caracterização da cadeia de suprimentos de óleos lubrificantes e a contextualização das exigências da legislação, bem como uma revisão teórica referente às barreiras encontradas para a implementação da GSCM. O método de pesquisa e os resultados são apresentados e discutidos, sinalizando limitações e oportunidades para pesquisas futuras.

\section{CONTEXTUALIZAÇÃO E BASE TEÓRICA}

Para contextualização da pesquisa revisou-se a cadeia produtiva do óleo lubrificante e a legislação aplicável. O referencial teórico no qual se embasa a pesquisa é composto pelas barreiras à implementação já identificadas por Govindan et al. (2014).

\section{I A CADEIA PRODUTIVA DO ÓLEO LUBRIFICANTE}

O óleo lubrificante é um derivado de petróleo utilizado em várias atividades, como em sistemas hidráulicos, motores, turbinas, ferramentas de corte, entre outros. No decorrer de sua utilização, ocorre a degradação termoxidativa e o acúmulo de contaminantes, tornando-se necessária a sua troca. O Óleo Lubrificante Usado ou Contaminado (OLUC), se descartado sem qualquer cuidado, pode acarretar prejuízos ambientais irreversíveis devido aos resíduos perigosos que contém, tais como metais pesados, ácidos orgânicos, hidrocarbonetos policíclicos aromáticos e dioxinas, todos classificados como perigosos. Na água, um único litro de óleo é capaz de esgotar o oxigênio de um milhão de litros de água; no solo, os metais pesados causam a contaminação das águas superficiais e dos lençóis freáticos; no ar, a queima lança substâncias carcinogênicas, como chumbo, cádmio, níquel, cromo, zinco e outras composições químicas (SINDIRREFINO, 2014).

O óleo lubrificante contaminado é resíduo, mas, ao mesmo tempo, uma fonte importante de óleo lubrificante básico, pois ele entra na composição do óleo lubrificante acabado na proporção entre $80 \%$ e $85 \%$. O Brasil é o quinto maior mercado de lubrificantes e, por consequência, o quinto maior gerador mundial de óleo usado. O pais não é auto-suficiente, pois o óleo que sai das refinarias é impróprio, só $2 \%$ pode ser aproveitado. Em 2011, foram produzidos e comercializados 234.948 milhões de litros de óleo básico duas vezes refinado (SINDIRREFINO, 2014).

A única forma legal e correta de reciclagem do óleo lubrificante usado é o rerrefino, que é um processo tecnológico capaz de extrair dos resíduos matéria-prima com a mesma qualidade do produto decorrente primeiro refino, atendendo às especificações técnicas estabelecidas pela Agência Nacional de Petróleo (ANP). Este processo torna o óleo um produto 100\% reutilizável, pois ele transformando-o em óleo mineral básico, resgatando as propriedades originais do produto. Desse modo, retorna para o mercado, podendo ser usado na fabricação de óleos lubrificantes acabados, cumprindo com o princípio de gerar o mínimo de danos ambientais (SINDIRREFINO, 2014).

A coleta do OLUC deve ser feita por um agente registrado na ANP, que, ao coletá-lo, é obrigado a encaminhá-lo, em sua totalidade, para o rerrefino. É proibido, por lei, todo e qualquer tipo de descarte de óleo na natureza, assim como é vedada a combustão ou incineração de óleo (SINDIRREFINO, 2014).

O revendedor é obrigado a receber do gerador (quem usou) o óleo usado, dispondo de instalações adequadas e licenciadas pelo órgão governamental para a coleta desse resíduo de forma segura, sem vazamentos e contaminações. O revendedor deve assegurar-se que o coletor está devidamente autorizado e também deve exigir-lhe o certificado de coleta. O coletor é a pessoa jurídica devidamente autorizada pela ANP e licenciada pelo órgão ambiental do Estado ou município para realizar atividade de coleta de óleo lubrificante usado ou contaminado no seu local de recolhimento (posto, oficina, indústria, etc.) 
e de transporte até a destinação a um rerrefinador. (SINDIRREFINO, 2014).

Na Figura 1 é possível observar a cadeia produtiva do OLUC. A Refinaria produz o óleo básico de diversas viscosidades, que então vai para o Produtor ou Importador, que incorpora aditivos para fazer o óleo lubrificante acabado, que é vendido para as Revendedoras Atacadistas ou Varejistas. Estas, por sua vez, vendem o óleo lubrificante acabado para Consumidores ou para Indústrias, Empresas de Transportes Coletivos ou de Cargas, os Governos, etc. (que já são, elas mesmas as consumidoras). O OLUC passa, então, por sua etapa decisória: ou ele vai para a coleta, sendo este o caminho que irá levá-lo até a produtora que passa a rerrefiná-lo, fechando, assim, o ciclo da Logística Reversa, ou quando existe a destinação e/ou descarte incorretos, o OLUC pode acabar contaminando água, solo ou ar. Na situação em que esse segundo caminho é tomado, o que acontece é que entre o gerador e o coletor pode haver desvio para outros fins, que não o rerrefino. Quando é desviado, o OLUC serve para combustível em caldeiras, olarias, tecelagens, fundições ou como lubrificante de motosserras, além de ser matéria-prima para empresas que recondicionam o óleo e o descartam de forma incorreta (SINDIRREFINO, 2014).

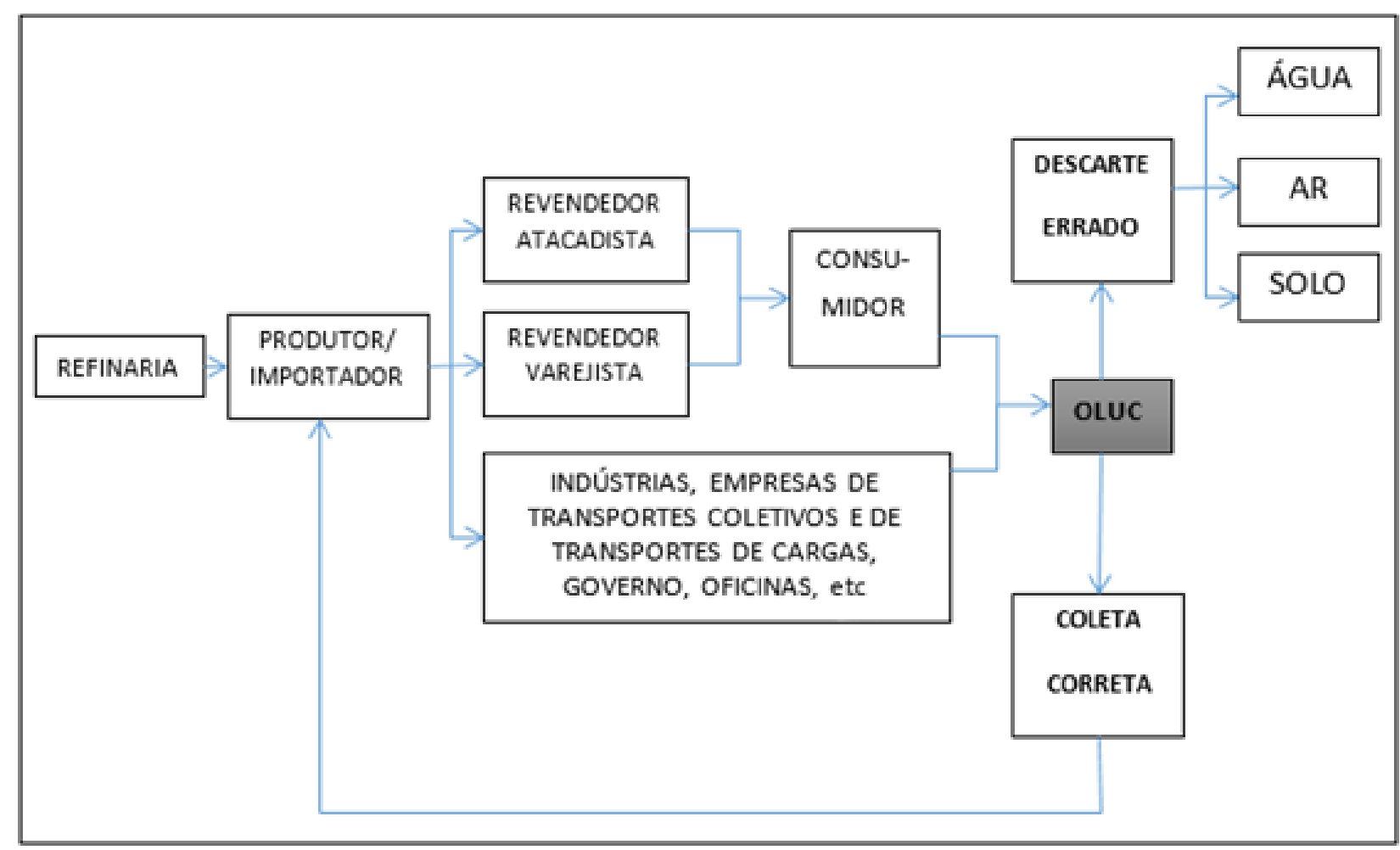

Figura 1: A cadeia produtiva do óleo lubrificante

Fonte: autores

\subsection{LEGISLAÇÃo}

A Resolução do CONAMA 362/2005 dispõe que o óleo lubrificante usado ou contaminado é um resíduo perigoso que apresenta toxicidade (NBR 10004) e, por isto, deverá ser recolhido, coletado e ter destinação final adequada, sendo o produtor e o importador de óleo lubrificante acabado os responsáveis pela coleta ou garantia de que a coleta tenha sido feita bem como dada destinação final OLUC. Um Grupo de Monitoramento Permanente foi criado e é coordenado pelos Ministérios do Meio Ambiente e de Minas e Energia com o objetivo de acompanhar a aplicação e a implementação dessa Resolução. Dentre as ações deste grupo está a publicação do Guia Básico de Gerenciamento de Óleos Lubrificantes Usados ou Contaminados (OLUC), do Manual de atividades relacionadas Óleos Lubrificantes Usados ou Contaminados e das Diretrizes para Óleos Lubrificantes Usados ou Contaminados (SINDIRREFINO, 2014).

Em 2010 foi promulgada a Lei ${ }^{\circ}$. 12.305, que institui a Política Nacional de Resíduos Sólidos (PNRS) e apresenta disposições referentes aos princípios, objetivos e instrumentos, bem como diretrizes 
relativas à gestão integrada e ao gerenciamento de resíduos sólidos, às responsabilidades dos geradores e do poder público e aos instrumentos econômicos aplicáveis. No Capítulo III, art. $8^{\circ}$ da Lei, temos os Instrumentos, dentre os quais: O SINIR (Sistema Nacional de Informações sobre a Gestão dos Resíduos Sólidos); o Inventário de Resíduos, que se somará ao Sistema Declaratório Anual de Resíduos Sólidos (preenchido e atualizado pelas indústrias, sinalizando a origem, transporte e destinação final dos resíduos); e o Cadastro Nacional de Operadores de Resíduos Perigosos (cadastro de pessoas jurídicas que operam com resíduos perigosos, em qualquer fase do seu gerenciamento). O IBAMA é o responsável por coordenar o Cadastro Técnico Federal de atividades potencialmente poluidoras ou utilizadoras de recursos ambientais acima das deliberações do SINIR (SINDIRREFINO, 2014).

O descumprimento da legislação prevê multas que podem chegar a milhões de reais e indiciamento por crime ambiental, crime de ordem tributária e crime contra o consumidor (SINDIRREFINO, 2014).

\subsection{RefERENCIAL TEÓRICO: BARREIRAS CONHECIDAS PARA A IMPLEMENTAÇÃO DA GSCM}

Em pesquisa empírica junto a fabricantes do Reino Unido, Holt e Ghobadian (2009) observaram que a legislação e as demandas internas às empresas, a exemplo da redução de custos, são os fatores que exercem maior pressão para aumentar o desempenho ambiental. Os direcionadores sociais e as pressões de clientes individualmente dentro da cadeia de suprimentos são, por sua vez, os que menos exercem pressão para melhorar a performance ambiental. Em geral, as empresas focam mais em soluções internas do que em iniciativas pró-ativas para engajamento em processos de outros stakeholders da cadeia de suprimentos (HOLT; GHOBADIAN, 2009).

Pesquisa de Zhu et al. (2013) junto a empresas chinesas das indústrias química, petroquímica, eletrônica, automotiva e mecânica sinalizam igualmente que as pressões institucionais (internas) são as que levam as empresas à implementar a GSCM para depois engajarem em direcionadores externos. A melhoria da performance econômica dessas empresas não é influenciada diretamente pela melhoria do desempenho ambiental, mas traz benefícios a logo prazo (ZHU et al., 2013). Em um estudo em pequenas e médias empresas naquele país, a legislação é, novamente, a que mais exerce pressão para a adoção da GSCM, seguido de pressão no processo de vendas de produtos e depois pressões fornecedores e clientes na própria cadeia de suprimentos (HUANG; TAN; LI, 2012).

$\mathrm{Na}$ indústria de mineração na Índia, a falta de uma consciência ambiental, a fraca legislação e pressões inadequadas da sociedade são as barreiras mais significativas para a adoção da GSCM (BARVE; MUDULI, 2013; TESTA; IRALDO, 2010). A pesquisa realizada por Govindan et al. (2014), por sua vez, apontou barreiras na área de tecnologia como a principal. Essa área compreende tecnologia em si mas também recursos específicos como materiais, processos e pessoas com conhecimento e expertise. Outra pesquisa realizada com empresas da Índia indicou que há diferenças significativas no tipo de pressão para a adoção da GSCM dependendo do tipo de indústria e do seu porte (XU et al., 2013).

No Brasil, estudos realizados junto a grandes empresas de tecnologia que possuem certificação na ISO 14001, indicou que a legislação continua sendo um direcionador importante para a adoção de práticas verdes. As empresas investigadas adotam compras verdes e práticas de ecodesign principalmente quando são exigidas pelos clientes dos fabricantes. Pouca pró-atividade foi observada na adoção de práticas verdes por essas empresas (JABBOUR et al., 2013). No Brasil, as práticas de GSCM ainda são tímidas se comparadas com outros países, revela pesquisa realizada com especialistas da área. Os autores atribuem a isso atrasos nas práticas organizacionais devido às características do mercado brasileiro e à falta de pressão por parte do governo com regulamentação e fiscalização mais objetivas e específicas (ALVES; NASCIMENTO, 2013).

A partir de revisão bibliográfica, entrevista com especialistas e survey em vários setores industriais, Govindan et al. (2014) identificaram 47 barreiras para a implementação da GSCM. Essas barreiras foram avaliadas por 103 empresas indianas que adotaram atividades ambientalmente amigáveis e dessas, 26 foram consideradas prioritárias. Os autores agruparam as barreiras em cinco categorias: terceirização, tecnologia, conhecimento, financeiro e envolvimento e apoio. As barreiras são apresentadas no Quadro 1 (GOVINDAN et al., 2014) e serviram como referencial teórico para a pesquisa de campo. 
Quadro 1: Barreiras identificadas para a implementação da GSCM (Fonte: Govindan et al., 2014)

\begin{tabular}{|c|c|c|}
\hline Tipo de barreira & & Barreiras \\
\hline \multirow{6}{*}{ Terceirização } & 1 & Produtos potencialmente conflitantes com o que estabelece a lei \\
\hline & 2 & Parceria ambiental com fornecedores \\
\hline & 3 & Falta de apoio do governo para adotar políticas ambientalmente amigáveis \\
\hline & 4 & Complexidade na medição e monitoramento de práticas ambientais de fornecedores \\
\hline & 5 & Problemas em manter fornecedores ambientalmente corretos \\
\hline & 6 & $\begin{array}{l}\text { Não há um sistema de treinamento e recompensa adequado para os fornecedores } \\
\text { que adotam posicionamento verde }\end{array}$ \\
\hline \multirow{9}{*}{ Tecnologia } & 7 & Falta de novas tecnologias, materiais e processos \\
\hline & 8 & Complexidade de projeto para reutilizar ou reciclar o produto \\
\hline & 9 & Falta de flexibilidade para mudar para um novo sistema \\
\hline & 10 & Complexidade de projeto para reduzir o consumo de recursos e energia \\
\hline & 11 & Falta de conhecimento técnico \\
\hline & 12 & Falta de recursos humanos \\
\hline & 13 & Dificuldade em transformar atitudes ambientais positivas em ação \\
\hline & 14 & Falta de medidas ambientais eficazes \\
\hline & 15 & Medo de falha \\
\hline \multirow{11}{*}{ Conhecimento } & 16 & Falta de profissionais com experiência em sistema verde \\
\hline & 17 & Problemas na identificação de terceiros para recolher produtos usados \\
\hline & 18 & Falta de conhecimento ambiental \\
\hline & 19 & Hesitação/ medo de converter para novos sistemas \\
\hline & 20 & Dificuldade de obter informações sobre potenciais melhorias ambientais \\
\hline & 21 & Falta de objetivo ambiental específico \\
\hline & 22 & Percepção de uma zona isenta de responsabilidades \\
\hline & 23 & Dificuldade para identificar oportunidades ambientais \\
\hline & 24 & Descrença nos benefícios ambientais \\
\hline & 25 & Falta de consciência sobre a logística reversa \\
\hline & 26 & Falta de eco-entendimento comum entre os parceiros da cadeia de suprimentos \\
\hline \multirow{9}{*}{ Financeiras } & 27 & Custo de embalagem ambientalmente amigável \\
\hline & 28 & Risco na estocagem de materiais perigosos \\
\hline & 29 & Alto custo de eliminação de resíduos perigosos \\
\hline & 30 & Restrições financeiras \\
\hline & 31 & Pouco crédito bancário para incentivar produtos e processos verdes \\
\hline & 32 & Recrutamento de recursos humanos adicionais \\
\hline & 33 & Despesas na coleta de produtos usados \\
\hline & 34 & Altos investimentos para baixo retorno \\
\hline & 35 & Custo da mudança para o novo sistema \\
\hline \multirow{7}{*}{$\begin{array}{l}\text { Envolvimento e } \\
\text { suporte }\end{array}$} & 36 & $\begin{array}{l}\text { Falta de cursos de treinamento/ consultoria / instituições que concebam, treinem e } \\
\text { monitorem progressos específicos }\end{array}$ \\
\hline & 37 & Falta de consciência do impacto ambiental sobre o negócio \\
\hline & 38 & Capacidade de gestão inadequada \\
\hline & 39 & Falta de conscientização do cliente e de pressão sobre GSCM \\
\hline & 40 & Competição de mercado e incertezas \\
\hline & 41 & Falta de Responsabilidade Social Corporativa \\
\hline & 42 & Falta de apoio e orientação das autoridades reguladoras \\
\hline
\end{tabular}




\begin{tabular}{|c|c|l|}
\hline Tipo de barreira & \multicolumn{2}{|c|}{ Barreiras } \\
\hline \multirow{4}{*}{43} & $\begin{array}{l}\text { Políticas restritivas da empresa em relação a pessoas responsáveis pelos produtos e } \\
\text { processos na GSCM }\end{array}$ \\
\cline { 2 - 3 } & 44 & Falta de compromisso do fornecedor ou falta de vontade de trocar informações \\
\cline { 2 - 3 } & 45 & Falta de cooperação interdepartamental na comunicação \\
\cline { 2 - 3 } & 46 & Baixo envolvimento em programas relacionados com o ambiente \\
\cline { 2 - 3 } & 47 & Falta de envolvimento da gerência superior em adotar o GSCM \\
\hline
\end{tabular}

\section{METODOLOGIA}

Fonte: Govindan et al., 2014

Com o objetivo de verificar quais barreiras para a plena implementação da GSCM são predominantes e relevantes para o contexto brasileiro, especificamente para uma empresa integrante da cadeira de suprimentos em óleos lubrificantes e, principalmente o motivo para tais barreiras, este artigo realizou uma pesquisa aplicada de abordagem qualitativa com objetivo exploratório. Segundo Silva (2005), uma pesquisa qualitativa busca a interpretação de fenômenos e a atribuição de significados; o ambiente natural é a fonte direta para coleta de dados e o pesquisador é o instrumento-chave. Pesquisas exploratórias visam possibilitar uma maior familiaridade com a questão investigada, de forma a explicitá-lo melhor ou construir hipóteses (GIL, 2008).

Quanto aos procedimentos técnicos, trata-se de um estudo de caso único. Este procedimento investiga fenômenos da atualidade através de eventos ou condições e seus relacionamentos, visando o entendimento destes fenômenos por meio múltiplas fontes de evidência e a partir delas permitir discussão dos resultados, interpretações e comparações (YIN, 2010).

A empresa estudada foi fundada em 1991 e conta com um quadro de aproximadamente 300 funcionários. Possui unidades de atendimento nos três estados da Região Sul do Brasil, além de dois centros de distribuição na região metropolitana de Porto Alegre. A empresa atua nos segmentos de revenda e prestação de serviços de manutenção em máquinas e equipamentos de grande porte (empilhadeiras, escavadeiras), e também como distribuidor de óleos lubrificantes e aditivos de grandes fabricantes. Como distribuidor, a empresa atua como uma intermediária entre a refinaria e os revendedores da ampla gama de produtos oferecidos. Dentre esses produtos estão: óleos lubrificantes automotivos da linha leve e pesada, óleos para sistemas hidráulicos, óleo para transmissão e óleos e graxas para usos industriais. A empresa também presta serviços técnicos, tais como atividades de manutenção e troca de óleo nas máquinas.

Esta empresa foi selecionada porque integra uma cadeia de suprimentos em que não é a empresa de maior poder econômico ou líder na articulação com toda a cadeia, o que pode trazer elementos novos para o estudo.

Seguindo as orientações de Yin (2010), foi elaborado o protocolo do estudo de caso, que compreendeu as principais fases da pesquisa de campo. O objetivo deste protocolo é definir a maneira como o trabalho será conduzido, assim como a data das visitas, tempo estimado e os recursos empregados para coletar as informações necessárias à realização do estudo.

As barreiras indicadas por Govindan et al. (2014) no Quadro 1 serviram como ponto de partida, mas sem a intenção de serem exclusivas, para verificar quais destas eram relevantes no contexto da GSCM de óleos lubrificantes no contexto brasileiro. Uma vez identificadas as principais barreiras, sob a ótica da empresa estudada, entrevista em profundidade buscou entender o motivo para a existência dessas barreiras.

O processo de coleta de dados ocorreu por meio de entrevistas e observação direta não participante na empresa pesquisada. As entrevistas foram conduzidas a partir de um roteiro pré-definido, semi-estruturado e não diretivo. Na entrevista, conforme Yin (2010), o entrevistador pode tanto indagar dos respondentes-chaves os fatos relacionados a um assunto, quanto pedir a opinião deles sobre determinados eventos.

Foram entrevistados o diretor da empresa, em entrevista de caráter mais geral sobre a própria empresa e o segmento, e duas entrevistas em profundidade junto ao responsável técnico para as questões ambientais. Com vistas a garantir a fidedignidade das informações, uma vez que não foi possível gravar as entrevistas, e para explorar as informações prestadas, as entrevistas foram realizadas com a 
presença de dois pesquisadores.

A análise de dados consistiu em examinar e cruzar as informações coletadas nas entrevistas e da observação direta na empresa.

\section{RESULTADOS E DISCUSSÃO}

A cadeia de óleo lubrificante no Brasil é fortemente legislada e monitorada por órgãos de controle públicos. A Legislação federal foi um forte estímulo para que as empresas se organizassem para a coleta e descarte adequado, não somente do óleo usado ou contaminado, como também das embalagens desses produtos. Uma das características do óleo, a sua reciclabilidade, é de especial interesse para a organização da cadeia. A reciclabilidade do óleo usado é um elemento importante não somente do ponto de vista ambiental, pois evita novas extrações e descartes inadequados, mas também econômico, pois o resíduos ainda possui valor a ser extraído e recuperado.

A cadeia de suprimentos verde está consolidada no Estado. Assim, as barreiras relacionadas à implantação da GSCM dizem respeito principalmente à sua manutenção no patamar atual de desempenho. Nesse sentido, as barreiras relacionadas a aspectos financeiros são as que foram consideradas mais relevantes pela empresa pesquisada.

O Quadro 2 apresentada uma síntese por tipo de barreira, dos achados de pesquisa.

Quadro 2: Percepção quanto aos impactos sobre a GSCM por categoria de barreiras

\begin{tabular}{|c|c|}
\hline Tipo de barreira & Impacto sobre a GSCM \\
\hline Terceirização & $\begin{array}{l}\text { - A responsável, conforme a legislação, pela coleta a } \\
\text { destinação do OLUC e das embalagens cabe à } \\
\text { produtora/importadora do produto. No entanto, essa } \\
\text { responsabilidade foi delegada à distribuidora, que segue as } \\
\text { determinações legais à risca. } \\
\text { - A área é bastante legislada e monitorada, o que não impede } \\
\text { de haver brechas na lei que impeçam } 100 \% \text { de retorno do } \\
\text { óleo usado ou contaminado bem como das embalagens. } \\
\text { - O único ponto da cadeia em que o comprometimento e o } \\
\text { envolvimento pode representar alguma barreira está na ação } \\
\text { dos usuários finais, que às vezes ignoram a necessidade de } \\
\text { retornar todas as embalagens e óleo utilizado. }\end{array}$ \\
\hline Tecnologia & Não foram identificadas barreiras críticas nessa área. \\
\hline Conhecimento & Não foram identificadas barreiras críticas nessa área. \\
\hline Financeiro & $\begin{array}{l}\text { Foram consideradas relevantes três barreiras: custo de } \\
\text { embalagem ambientalmente amigável; alto custo na } \\
\text { eliminação de resíduos perigosos, e despesas na coleta de } \\
\text { produtos usados. }\end{array}$ \\
\hline $\begin{array}{l}\text { Envolvimento e } \\
\text { suporte }\end{array}$ & $\begin{array}{l}\text { A gestão ambiental é uma premissa para a empresa e, } \\
\text { portanto, está incorporado na cultura organizacional a } \\
\text { necessidade de ações ambientalmente corretas. Por esta } \\
\text { razão, não foram consideradas como barreiras para a } \\
\text { empresa. }\end{array}$ \\
\hline
\end{tabular}

Fonte: autores 
Dentre as barreiras identificadas, quatro foram apontadas como críticas para a empresa: a parceria ambiental com os fornecedores; o custo de embalagem ambientalmente amigável; o alto custo de eliminação de resíduos perigosos; despesa na coleta de produtos usados. O primeiro está relacionado a barreiras de terceirização e os outros três a barreiras que impactam no desempenho financeiro. A empresa pesquisada integra a cadeia como distribuidora. A legislação estabelece que a responsabilidade pela coleta a destinação do OLUC e das embalagens cabe à produtora ou importadora do produto

No entanto, não é isso que se observa nessa cadeia no Estado do Rio Grande do Sul. Em relação às embalagens, a produtora isenta-se de responsabilidade ao terceirizá-la para a empresa distribuidora. Por esta razão, acaba sendo a liderança na gestão da destinação dos resíduos (embalagens), organizando a cadeia para que não ocorra problemas e estabelecendo uma série de controles para tal. A distribuidora responde pela maior parte do gerenciamento da logística reversa do óleo lubrificante em relação às embalagens. Para isso, conta com o apoio de empresas terceirizadas. Apesar de a parceria ambiental ser crítica, podendo ser uma barreira, há um comprometimento por parte dos parceiros, recolhimento do óleo usado ou contaminado e das embalagens e disposição final destes. A fragilidade, embora não muito significativa, está no cliente que faz uso do óleo. A falta de conhecimento ou a falta de comprometimento leva a não entender a importância da devolução das embalagens. Essa dificuldade é enfrentada pro-ativamente pela empresa. Quando constatados casos similares, a empresa faz contato com o cliente explicando o fluxo e lembrando que essa ação não tem custo para ele (o cliente). "É um fluxo natural, automático: vende e coleta".

Também na questão do relacionamento com o cliente, a devolução de embalagens, em relação à legislação, tem algumas fragilidades conhecidas. Diferentemente do que acontece com baterias de carro, por exemplo, em que o cliente só pode comprar uma nova se devolver a velha, a obrigatoriedade de devolução não está condicionada à aquisição do novo produto. A legislação prevê apenas o recolhimento, não estando, também, vinculado à obrigatoriedade do produtor recolher somente os produtos da sua marca. Isso faz com que um fornecedor possa recolher embalagens de outras marcas, dificultando o controle sobre isso.

A coleta do OLUC é feita para a empresa por fornecedores ambientalmente certificados e autorizados a realizar tal atividade. A empresa conta também com serviços especializados terceirizados a fim de atualizá-la nas demandas de legislação e dar treinamento sempre que necessário. Não há dificuldades em transformar a lei em ação devido à cultura da empresa na adoção de práticas ambientalmente amigáveis.

As barreiras relacionadas à tecnologia dizem respeito à existência de recursos - tecnologias, propriamente, mas também pessoas, conhecimento técnico, projetos adequados, medições de desempenho - para atender às demandas ambientais. Para a empresa pesquisada, isso não é uma preocupação. A necessidade de atender aos aspectos da legislação e a própria cultura organizacional que tem preocupação ambiental faz com que não haja problemas nesse sentido. Profissionais especializados terceirizados são contratados para manter a empresa atualizadas quanto às questões de legislação e para garantir que os colaboradores entendam os princípios e procedimentos necessários para uma gestão verde. Por essas razões, também, barreiras relacionadas a conhecimento e a envolvimento e suporte interno à empresa não foram consideradas relevantes.

Nas barreiras relacionadas à questão financeira, três foram consideradas relevantes: custo de embalagem ambientalmente amigável; alto custo na eliminação de resíduos perigosos, e despesas na coleta de produtos usados. As três barreiras apontadas dizem respeito a um mesmo processo: o recolhimento das embalagens nos clientes consumidores. O Sindicato Nacional das Empresas Distribuidoras de Combustíveis e de Lubrificantes possui programa para recolhimento das embalagens. No entanto, a periodicidade do recolhimento é muito longa, o que obriga a empresa estudada a contratar empresas terceirizadas para realizar a tarefa, ou então o volume de material a ser recolhido é maior do que o Sindicato consegue realizar. A perspectiva é de aumento nestes custos, dado que a cada ano a demanda aumenta.

\section{CONCLUSÃO}

O aumento da demanda por óleo lubrificante gera a necessidade de adaptação dos integrantes 
da cadeia produtiva. No Brasil, existem normas que regulamentam o setor de forma abrangente, com ações específicas em alguns casos, como nas responsabilidades a respeito da coleta de embalagens, porém, a lei deixa lacunas em alguns momentos, como na possibilidade de a coleta ser feita sem um controle de quem vendeu a embalagem nova - o que pode causar diferenças entre o que foi vendido e o que foi coletado.

A empresa estudada tem buscado se enquadrar na legislação, até mesmo para não ser autuada, com pagamento de expressivas multas. Mas, independentemente da ação regulatória exercida pelo poder público, a empresa também possui práticas ambientalmente amigáveis nas suas ações internas, com programas de reciclagem e constante treinamento junto aos colaboradores. Verifica-se que a posição da empresa é de que a legislação está sendo cumprida e que a cadeia verde, portanto, está plenamente estabelecida. A empresa orgulha-se, inclusive, de não ter sido multada uma única vez por problemas ambientais. No entanto, esta é uma percepção questionável, uma vez que a gestão ambiental é uma prática de anos recentes no Brasil e dificilmente estaria consolidada e funcionando perfeitamente.

A partir de um estudo de caso, a questão de pesquisa procurou saber quais barreiras são mais significativas no gerenciamento da cadeia verde de óleo lubrificante e qual a razão para isso. As questões financeiras e externas (comprometimento de todos os parceiros na cadeia), foram os elementos que ficaram evidenciados nesta pesquisa. No entanto, considerando que um único caso foi estudado, esta pesquisa apresenta limitações que também se constituem em oportunidade de pesquisas futuras.

Certamente para se ter uma percepção mais sólida das barreiras que dificultam o gerenciamento da GSCM na cadeia de óleo lubrificante, seria necessário estudar os vários stakeholders da cadeia. Atenção também deveria ser dada ao OLUC a partir dos vários envolvidos na cadeia. Por fim, pesquisa quantitativa seria de utilidade para trazer a percepção das barreiras de fato no âmbito nacional e não apenas local.

\section{REFERÊNCIAS}

ALVES, A.; NASCIMENTO, L. Green supply chain management: protagonista ou coadjuvante no cenário brasileiro? SIMPOI. Anais...2013

BARVE, A.; MUDULI, K. Modelling the challenges of green supply chain management practices in Indian mining industries. Journal of Manufacturing Technology Management, v.24, n.8, p.1102-1122, 2013.

BRITO, R.; BERARDI, P. Vantagem competitiva na gestão sustentável da cadeia de suprimentos: um metaestudo. RAE: Revista de Administração de Empresas, v.50, n.2, p.155-169, 2010.

GIL, A. Como elaborar projetos de pesquisa. São Paulo: Atlas, 2008.

GOVINDAN, K.; KALIYAN, M.; KANNAN, D.; HAQ, A. Barriers analysis for green supply chain management implementation in Indian industries using analytic hierarchy process. International Journal of Production Economics, v.147, n.3, p.555-568, 2014.

GREEN JR, K.; ZELBST, P.; MEACHAM, J.; BHADAURIA, V. Green supply chain management practices: impact on performance. Supply Chain Management: An International Journal, v.17, n.3, p.290-305, 2012.

HOLT, D.; GHOBADIAN, A. An empirical study of green supply chain management practices amongst UK manufacturers. Journal of Manufacturing Technology Management, v.20, n.7, p.933-956, 2009.

HUANG, X.; TAN, B.; LI, D. Pressures on Green Supply Chain Management : A Study on Manufacturing Small and Medium-Sized Enterprises in China. International Business and Management, v.4, n.1, p.76-82, 2012.

JABBOUR, A.; AZEVEDO, F.; ARANTES, A.; JABBOUR, C. Green supply chain management in local and 
multinational high-tech companies located in Brazil. The International Journal of Advanced Manufacturing Technology, v.68, n.1-4, p.807-815, 9 abr. 2013.

SARKIS, J.; ZHU, Q.; LAI, K. An organizational theoretic review of green supply chain management literature. International Journal of Production Economics, v.130, n.1, p.1-15, 2011.

SELLITTO, M.; BORCHARDT, M., PEREIRA, G. ; PACHECO, D. Gestão de cadeias de suprimentos verdes: quadro de trabalho. Produção Online, v.13, n.1, 351-374, 2013.

SINDIRREFINO - SINDICATO NACIONAL DA INDÚSTRIA DO RERREFINO DE ÓLEOS MINE-

RAIS. Disponível em: www.sindirrefino.org.br. Acesso em 10/03/2014.

SRIVASTAVA, S. Green supply-chain management: A state-of-the-art literature review. International Journal of Management Reviews, v. 9, n.1, p.53-80, 2007.

SRIVASTAVA, S. Network design for reverse logistics. Omega, v.36, n.4, p.535-548, 2008.

TESTA, F.; IRALDO, F. Shadows and lights of GSCM (Green Supply Chain Management): determinants and effects of these practices based on a multi-national study. Journal of Cleaner Production, v.18, n.10-11, p.953-962, 2010.

XU, L.; MATHIYAZHAGAN, K.; GOVINDAN, K.; HAQ, A.; RAMACHANDRAN, N.; ASHOKKUMAR, A. Multiple comparative studies of Green Supply Chain Management : Pressures analysis. Resources, Conservation \& Recycling, v.78, n.1, p.26-35, 2013.

YIN, R. Estudo de caso: planejamento e métodos. Porto Alegre: Bookman, 2010.

ZHU, Q.; SARKIS, J.; LAI, K. Examining the effects of green supply chain management practices and their mediations on performance improvements. International Journal of Production Research, v.50, n.5, p.13771394, 2012.

ZHU, Q.; SARKIS, J.; LAI, K. Institutional-based antecedents and performance outcomes of internal and external green supply chain management practices. Journal of Purchasing and Supply Management, v.19, n.2, p.106-117, 2013. 